\title{
Busca e Apreensão em Dependências Comerciais de Bancos
}

- Resposta à contribuição de Ranft, publicada em WiB 1996, 49 -

Sexhaxd Laule/ Prankfuxt a. ell.

Advogado e integrante dos escritórios de advocacia Feddersen Laule Scherzberg \& Ohle Hansen Ewerwahn. Trabalha como advogado

em ações de buscas em dependências comerciais de bancos.

Traduzido por Peter Naumann - Revisão técnica de F. A. Gernot Lippert

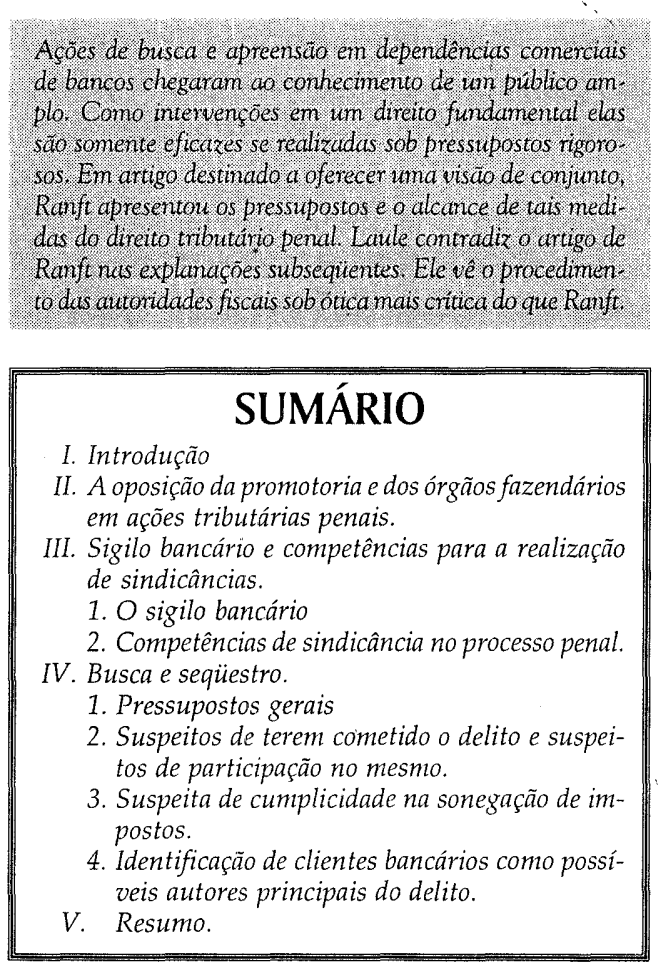

Kruse, DStJG 6 (1983), 1

2. Raab, no diário Frankfurter Allgemeine Zeitung de 4.11.1996, B 14 (em outro contexto); v. também Tribunal Regional de Stuttgart (AG 1996, 561), que formula uma crítica caracterizada por extremada falta de objetividade e polemiza com coloração política.

\section{Introdução}

á em 1982 um levantamento efetuado pela Sociedade Alemã de Direito Tributário revelara que por um lado já não predominam mais situações arcaicas no âmbito do direito tributário penal, embora, por outro lado, ainda subsistam consideráveis déficits jurídicos de natureza prática e teórica ${ }^{1}$. Diante das experiências mais recentes em sindicâncias tributário-penais contra bancos deve-se constatar que esse quadro pouco mudou. E somos obrigados a constatar o seguinte: "Os tempos dos bancos como instituições veneráveis, intocáveis... pertencem definitivamente ao passado." 2

Antigamente uma raridade, as buscas e apreensões em bancos por motivos de Direito Penal Tributário aumentaram con- 
sideravelmente ${ }^{3}$. Destarte aumentou tam bém o volume da bibliografia especializada até agora esparsa. Haecker ${ }^{4}$ parece ter sido o primeiro a se ocupar, em 1953, com as questões jurídicas materiais, especialmente com a da eventual cumplicidade de funcio nários de bancos na sonegação de impostos por parte de clientes do banco. Quase trinta anos depois, Philipowski ${ }^{5}$ retomou a su argumentação e procurou, mais especificamente, avaliar de forma diferenciada punibilidade de funcionários de bancos mediante recurso à doutrina da adequação social. A idéia foi retomada em 1995 po Hassemer no sentido de uma "adequação

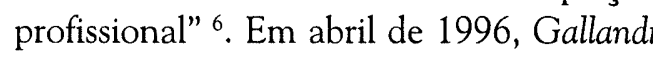
contrapôs a Hassemer - infelizmente sem registrar a proposta adicional de solução apresentada por Löwe-Krahl ${ }^{7}$ e argumen tando, ao que parece, conscientemente for do âmbito do direito penal tradicional - a "criminalidade profissionalmente adequada" 8 .

Diante da atualidade candente des sa temática, é compreensível a ocorrência de controvérsias na área das ações tributá rias penais, que de momento estão em pri meiro plano. Na mesma ocasião, Rüping ocupou-se especialmente com a busca na ação tributária penal, criticando nessa oca-

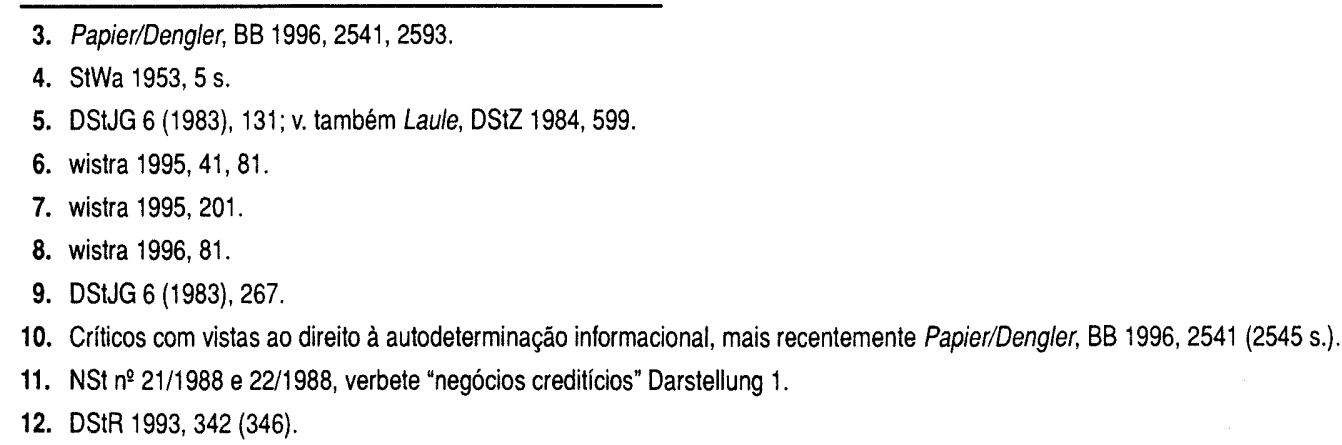

12. DStR $1993,342(346)$

sião o universo ultrapassado, no qual o direito codificado vigente fazia sentido ${ }^{10} \mathrm{e}$ chamando a atenção aos imperativos constitucionais a serem observados nesse contexto. Há quase dez anos Müller-Brühl tratou extensamente, embora ainda de forma bem pouco dramática, especialmente a posição das instituições creditícias em ações tributárias contra os seus clientes ${ }^{11}$. Vista a partir da perspectiva atual, a advertência de Streck ${ }^{12}$ quase assume ares de profecia. Na 15a Jornada dos Consultores Tributários da Alemanha, em 1992 e com vistas à propaganda dos bancos para aplicações de capitais no exterior, esse autor alegara que a sua imaginação seria suficiente para supor que "qualquer repartição de perseguição penal ou qualquer promotoria pública poderia levantar a suspeita de instigação ou cumplicidade", encerrando as suas explanações com uma observação lacônica: "Os bancos dispõem de grandes departamentos jurídicos e devem ter examinado o que estão publicando".

No contexto das buscas e apreensões efetuadas em um grande banco alemão, as questões atinentes ao direito processual em ações tributárias penais ganharam mais tarde um especial impulso, mormente em virtude das duas decisões

Revista da Faculdade de Direito da UFRGS, v. 16, 1999 da Corte Constitucional Federal em $1994^{13}$. Essas decisões provocaram muitos posicionamentos críticos ${ }^{14}$, como a própria corte registra concisamente e sem se afastar da sua posição ${ }^{15}$, mas elas também encontraram defensores mais ou menos engajados ${ }^{16}$. Parece que Ranft também deve ser incluído nesse último grupo, apesar de várias indicações de cunho crítico; seu artigo amplamente dimensionado sobre "Busca e apreensão em dependências comerciais de bancos" 17 ocupa-se primacialmente com esse caso apesar da formulação abstrata do tema e exige uma resposta, ao menos com referência às explanações de carạ́ter fundamentador ${ }^{18}$. Nessa resposta sigo èm grande parte a estrutura do artigo de Ranft, para possibilitar uma orientação geral mais simples.

\section{A posição da promotoria e dos órgãos fazendários em ações tributárias penais}

Já a primeira frase de Ranft, segundo a qual as buscas e apreensões em bancos teriam "quase sempre" origem em uma mo-

tivação tributária penal, provoca uma observação crítica que no entanto é dirigida menos contra Ranft e mais contra a tendência geral. Não há como fugir à pergunta se talvez não estejamos mais diante do direito penal e da ação penal no sentido tradicional. Ransieck ${ }^{19}$ dá uma resposta que atinge o cerne do problema: "Na pauta não estão mais as sindicâncias para a constatação da responsabilidade em termos juspenalistas, mas os problemas estruturais da ação penal de cuja solução a Corte Constitucional Federal [...] encarregara com boas razões o legislador, tocante à tributação dos juros. A solução pelo Direito Penal leva necessariamente a fricções. No fundo a punibilidade de indivíduos não interessa. Muito pelo contrário, o objetivo é a própria busca: ela é a 'pena', pois as buscas iminentes visam impedir as operações anônimas de pagamentos entre a Alemanha e o Luxemburgo."

Estaria o processo penal se transformando em meio da política financeira, sem estar devidamente instrumentado para 0 cumprimento de tal tarefa? Não se pode permitir que isso aconteça ${ }^{20}$.

13. Decisōes da $2^{\mathrm{a}}$ Câmara do Segundo Senado de 23.3.1994, wistra 1994, $221=\operatorname{StV}$ 1994, 353 com notas de Streck, bem como p. 409 com notas de Otto, e 13.12.1994, wistra 1995, 139.

14. Krekeler/Schütz, wistra 1995, 296; Leisner, B 1994, 1941; Id. BB 1995, 525; Ransiek, EWiR Art. $13^{\circ}$ da Constituiçăo Federal da Alemanha 1/94, 573; Schuhmann, wistra 1995, 336; Trzaskalik, DB 1994, 550, bem como ultimamente Papier/Dengler, BB 1996, $2541,2593$.

15. Decisão de 13.12.1994, loc. cit:; cí. para tal criticamente Leisner, BB 1995, 525

16. Carr/Klos, wistra 1994, 211; Streck, StV 1994, 355 (nota sobre a sentença).

17. WiB $1996,49$.

18. WiB 1996, 49 (49-52), seçóes $1-111$

19. EWiR, Constituição Federal da Alemanha, Art. 13ำ1/94, 537.

20. Assim, pertinentemente, Leisner, BB 1995, 525 (528); criticamente também Papier/Dengler, BB 1996, 2541 (2543).

** $A O=$ Abgabenordnung, Código Tributário Nacional [N. do T.]

${ }^{* *}$ StPO $=$ Strafprozessordnung, Código de Processo Penal [N. do T.] 

única ou periódica", proibida por $\mathrm{AO} \S 30$ calização"; mas cf. AO § 30 a III a expressão

\section{Sigilo bancário e \\ competências para a realização de sindicâncias}

Devemos delimitar o sigilo bancário e as competências para a realização de sindicâncias.

\section{0 sigilo bancário}

Deve-se concordar grandemente com as explanações de Ranft sobre o sigilo bancário. Mas quero dar ao menos algumas indicações terminológicas com referência a três itens menores:

Ranft infere de $\mathrm{AO}^{* *} \S 30$ a II "que não se pode exigir comunicações de controle dos bancos"; se é que se necessita de uma denominação para a "comunicação a II "para fins de fiscalização geral", ela po deria ser denominada "comunicação de fis "comunicação de controle" estaria desgastada. Ranft infere outrossim de $\mathrm{AO}$ $\S 30$ a II que "não se deve efetuar qualquer "busca sistemática [Rasterfahndung], des de que ela não se baseie em suspeita concreta de delito".

Com "busca sistemática" certamen te não se faz aqui nenhuma referência ao procedimento conforme $\mathrm{StPO}{ }^{* * *} \S 98$ a pois, como Ranft reconhece, $\mathrm{AO} \S 30$ a é

uma prescrição do processo de inquérito fiscal, não do processo penal ${ }^{21}$. Pensa-se aqui, muito pelo contrário e em linguagem não-técnica, na coibição de pedidos de informação coletiva de saldos de contas, prescrita por $\mathrm{AO} \S 30$ a II, especialmente na coibição do controle sistemático de grupos inteiros de pessoas tributáveis segundo "grades de suspeitas" 22 . O posicionamento de Ranft contra a "busca sistemática" nesse sentido deve ser saudado como muito positiva quanto ao seu mérito intrínseco, já que existem também tendências contrárias ${ }^{23}$ e pedidos de informação dimensionados com excessiva amplitude ocorrem na prática sempre de novo, mesmo sem a existência de "suspeita concreta de delito" ${ }^{24}$. Assim observei e apresentei queixa contra o fato de que toda e qualquer aplicação de capitais no valor de DM 500.000,- - ou em valores superiores põe em marcha o mecanismo da busca de informações coletivas por parte do serviço de repressão a fraudes fiscais ${ }^{25}$. De qualquer modo deve-se reter que pedidos de informações sem pontos concretos para circunstâncias fiscalmente relevantes, especialmente "buscas sistemáticas" ou sindicâncias similares são inadmissíveis: o órgão fazendário não pode apresentar pedidos de informação "apenas para ver em que isso vai dar" ["ins Blaue hinein"] ${ }^{26}$.

\section{Tipke/Kruse, Komm. z. AO/FGO, Tz. 1 zu AO § a; cf. também AO $\$ 30$ a I com remissão a AO $\S 88$.}

22. Tipke/Kruse (v. nota de rodapé 21, supra), Tz. 5 zu AO $\$ 30 \mathrm{a}$.

23. Carl/Klos, wistra 1994, 211 (215); criticamente, Lüders/Meyer-Kessel, DB 1990, 1790; a esse respeito também Schuhmann, wistra 1995, 336 (337)

24. Assim, no entanto, Rantt, WiB 1996, 49.

25. Contra tal tendência também expressamente Kühn/Hoffmann, Abgabenordnung, nota 3 sobre AO $\S 30$ a.

26. BFH, BStBl 1991 II, 277 (278).
Para pedidos de informação a instituições bancárias vale conforme $\mathrm{AO} \S 30$ a $\mathrm{V}$ I a prescrição de $\mathrm{AO} \S 93$. Ranft enfatiza com razão a subsidiaridade do dever de informação conforme $\S 93$ I 3 em combinação com $\mathrm{AO} \S 30$ a V 2. Conforme $\mathrm{AO} \S$ 30 a V 2 a subsidiaridade vale para pedidos de informação a instituições bancárias em todos os procedimentos conforme $\mathrm{AO} \S$ 20811 , se a pessoa tributável for conhecida e nenhuma ação tiver sido apresentada uma contravenção fiscal. Com isso a extinção da vigência da subsidiaridade para processos conforme $\mathrm{AO} \S 208 \mathrm{I} 1 \mathrm{n}^{\circ}$ 3, que normalmente beneficia os órgãos de repres são de fraudes fiscais, fica novamente revogada para as instituições bancárias ${ }^{27}$, em outras palavras, a subsidiaridade está restituída.

\section{Competências de sindicância no processo penal}

Procede a inferência de Ranft a par tir de $\mathrm{StPO} \S 53$ e de $\mathrm{AO} \S 102$ de que os funcionários de bancos não podem invocar o direito de negação de testemunho por razões profissionais. Mas como eles devem contar, apesar da adequação profissional da sua atuação ${ }^{28}$, com a eventual acusação da cumplicidade na sonegação de impostos, a lembrança do direito de negação a prestar contra ela em virtude de um delito ou de informações, baseado em StPO $\S 55$, provavelmente teria sido oportuna 29.

Procede também a lembrança de Ranft de que não assistem aos bancos direitos especiais referidos à profissão a partir de GG ${ }^{* * *}$ Art. $12^{\circ}$ I, no sentido de um sigilo bancário que continua também existindo em processos penais. Mas Ranft não formulação crítica de que a Corte Constitucional Federal deveria ter feito a constatação "aparentemente necessária, mas em si evidente per se", pois a liberdade do exercício profissional dos bancos mere. ce um exame no contexto das buscas realizadas pelo serviço de repressão a fraudes fiscais. Isso é mostrado também pelas cone mormente pelas de Papier/Dengler ${ }^{31}$ sobre os danos à reputação resultantes de medidas processuais penais. $O$ fato de Ranft somente dar reduzida importância a essa dimensão é evidenciado pelas suas explanações subseqüentes ${ }^{32}$.

\section{Busca e sequestro}

Em primeiro momento, a busca e a apreensão estão vinculadas a pressupostos de caráter geral e dirigem-se preferencialmente contra pessoas expostas à suspeita de terem prestado ajuda na sonegação de impostos. pode fugir à pergunta pelas razões da sua siderações pertinentes de Krekeler/Schütz ${ }^{30}$

27. Cf. Tipke/Kruse (nota de rodapé 21, supra), Tz. 8 sobre AO $\S$ a 30 a.

28. Cf. Hassemer, wistra 1995, $41,81$.

29. Causa espécie que Ranft discuta o assim chamado princípio nemo tenetur somente por ocasião da garantia de dados de computadores, citando a propósito StPO § 136 I2, mas não StPO § 55 (WiB 1996, 56, Seção X, n* 1).

**** GG = Grundgesetz, Lei Fundamental. Designação da consitituição da República Federal da Alemanha. [N. do. T]

30. Die Durchsuchung von bzw. in Unternehmen, wistra 1995, 296 (299).

31. BB 1996, 2541 (2545), 2593 (2597).

32. Seção III, no 4 b; a respeito disso, cf. aqui pp. 23 ss. 


\section{Pressupostos gerais}

Ranft se manifesta de forma muito engajada no contexto de GG Art. $12^{\circ}$, mas silencia em contrapartida onde GG Art. 13응 I deveria ser discutido no contexto dos pressupostos gerais da busca e da apreensão, pois além do seu teor literal, a prescrição protege também dependências comerciais e autoriza pessoas jurídicas a invocar a proteção do direito fundamental ${ }^{33}$. Do mesmo modo falta aqui um aceno à proporcionalidade enquanto emanação do princípio do Estado de Direito ${ }^{34}$. Tais deficiências conduzem à interpretação falha da StPO enquanto legislação infraconstitucional.

É verdade que Ranft explica pertinentemente quem pode determinar uma busca (STPO § 1051). Mas apesar do título aqui reproduzido, ele bem como outros autores não discutem como o juiz primacialmente competente chega à certeza de que os pressupostos necessários existem, pois é tarefa do juiz o exame independente e neutro se a ação requerida é legamente admissível segundo as circunstâncias do caso, se, portanto, a intervenção no direito fundamental parece atender ao princípio da proporcionalidade ${ }^{35}$, e especialmente também se os interesses da pessoa afetada são suficientemente considerados ${ }^{36}$. Justamente nesse tocante parece ter havi-

do deficiências em ações contra instituições individuais do setor bancário; e deve-se temer, mais genericamente, que a reserva do juiz há muito tempo não cumpre mais o seu papel de "uma espécie de proteção jurídica preventiva" ${ }^{37}$ na prática do dia a dia. Por isso Streck ${ }^{38}$ relata pertinentemente que advogados defensores em processos tributários penais via de regra desrecomendam recorrer de mandados de busca em ações tributárias penais, "pois a confirmação dos mandados pelos tribunais de primeira instância e pelos tribunais regionais [Landgerichte] costuma ser a regra...". Esse diagnóstico vale ainda mais para a "formulação tão concreta quanto possível do mandado de busca", exigida por Ranft ${ }^{39}$; infelizmente a prática desconhece a "limitação adequada das medidas coercitivas", que ela visa assegurar.

Nem Ranft desconhece que os pressupostos da busca sejam formulados mais estreitamente em outras pessoas (STPO § 103) do que no caso de suspeitos (STPO $\S$ 102). Mas ele não expõe detalhadamente os limites mais estreitos, mas satisfaz-se com uma breve menção do seu manual ${ }^{40}$. Talvez resida aqui a razão de uma certa falta de nitidez da sua investigação subseqüente, na qual chama a atenção ao fato de que os suspeitos de terem cometido a ação

33. Rüping, DStJG 6 (1983), 267 (268); Papier/Dengler, BB 1996, 2593 (2597).

34. Cl. Rüping, DStJG 6 (1983), 273, bem como Papier/Dengler, BB 1996, 2593

35. Krekeler/Schütz, wistra 1995, 296 (298), com documentação adicional.

36. Rüping, DStJG 6 (1983), 274.

37. Ranft, WiB 1996, 52 (Seção IV letra a).

38. Nota à sentença StV 1994, 355.

39. Ranft, WiB 1996, 49 (53) (Seção IV, letra b).

40. Ranft, Strafprozessrecht, $2^{\circledR}$ ed. (1995), Rdn. 1006 ss. delituosa e os suspeitos de participação na mesma estão em primeiro plano, aparecen do as outras pessoas apenas marginalmen te ${ }^{41}$.

\section{Suspeitos de terem cometido o delito e suspeitos de participação no mesmo}

Ranft discute inicialmente a busca junto a suspeitos. Em concordância com a opinião preponderante, constata que os autores ou participantes só podem ser pes soas físicas, i.e, não um banco organizado como pessoa jurídica; o mesmo vale para sociedade comercial de capital aberto [oHG] ou para a sociedade em comandita ${ }^{42}$.

Ranft descuida no entanto que STPO $\S 102$ regulamenta a busca apenas "junto ao suspeito", i. é, junto "à pessoa que é suspeita de ter cometido um delito ou de ter participado nele". No caso do suspeito as sim caracterizado pode ser efetuada "uma vistoria da residência e de outras dependên cias bem como da própria pessoa e das coi sas que lhe pertencerem". Pode se depreender sem dificuldade do simples teo literal da lei que se deve tratar de depen dências que - como a pessoa do suspeito as "coisas que lhe pertencerem" - fazem parte de uma esfera protegida para ele. Mas isso não vale para a "área dos objetos definidores do lugar de trabalho" de um funcionário bancário subalterno. De acordo com a opinião preponderante ${ }^{43}$, tal posição somente compete a pessoas que são, enquanto órgãos ou representantes da pessoa jurídica ou de uma sociedade de pessoas, investidas de competências, (co-) titulares do direito domiciliar \{Hausrecht], mas não no caso de uma mera detenção em nome e cumprimento de ordens ou instruções de outrem ${ }^{44}$.

Não devemos ceder à ilusão de que por isso o mandado de busca contra o banco enquanto uma terceira pessoa "distinta" seria examinado sob o crivo das exigências mais rigorosas de STPO $\S 103{ }^{45}$. Ranft compreende a sentença da Corte Constitucional Federal de 23.3.1994 ${ }^{46}$ no sentido de que a suspeita recaiu sobre a organização do banco afetado enquanto totalidade, portanto "no caso eventual sobre a liderança da empresa". Com efeito, as passagens da sentença citada por Ranft podem ser lidas como se a Corte Constitucional Federal identificaria a presidência do banco como suspeita ou como se ela, de qualquer modo, concordaria com que os tribunais especializados partissem de um tal diagnóstico. Em no II 2.a (2) das razões ${ }^{47}$ lemos conforme segue: "Com vistas a isso não cabia criticar, do ponto de vista do direito constitucional, a existência de uma suspei-

41. Isso vale e.g. também para as exigências quanto à suspeita de encontrar documentos comprometedores, consideravelmente menores no caso do suspeito: cf. Ranft, WiB 1996, 49 (53) (Seção IV, letra b).

42. Krekeler/Schütz, wistra 1995, 296 (297), com documentaçäo adicional.

43. Krekeler/Schütz, wistra 1995, 296 (297), com documentaçáo adicional.

44. Krekeler/Schütz, wistra 1995, 296 (297), com documentação adicional, bem como Rüping, DStJG 6 (1983), 270.

45. Isso é criticado também por Papier/Dengler, BB 1996, 2593 (2599).

46. BVer'GE, wistra 1994, $221=$ SIV 1994, 353

47. wistra 1994, 221 (222) = StV 1994, 353 (354), respectivamente no centro da coluna direita. 
ta inicial de que se abusava sistematicamente e em grande estilo da organização da requerente e da sua sucursal luxemburguesa estava sendo abusada sistematicamente para a prestação de ajuda na sonegação do imposto de renda e do imposto sobre o patrimônio". E em n ${ }^{\mathrm{O}}$ II.2.b das razões ${ }^{48} \mathrm{se}$ afirma: "Os órgãos executores da sindicância não estavam proibidos de partir da hipótese de que toda a estrutura da requerente está inserida no prática do delito".

Quem deve ter abusado aqui sistematicamente da organização de um banco, quem deve ter inserido toda a sua estrutura na prática do delito? A presidência, os clientes ou determinados funcionários, talvez desencaminhados ${ }^{49}$ ? Contra a compreensão de Ranft de que a suspeita se estenderia à liderança da empresa, deve-se lembrar que conforme a sentença da Corte Constitucional Federal de 23.3.1994 "somente foi mencionada nominalmente a (funcionária) acusada" como autora e participante dos delitos tributários perseguidos, em combinação com a menção de que os clientes ainda desconhecidos não foram apenas apoiados por essa "acusada", mas também por todo um grupo de outros "funcionários" por ora ainda desconhecidos 50

Se portanto os suspeitos foram apenas a funcionária acusada bem como ainda outros funcionários por ora ainda desconhecidos do banco e provavelmente também

os ainda desconhecidos clientes do banco, a presidência não foi declarada suspeita. Por conseguinte, não poderia ter sido permitida a busca nos dependências do banco conforme STPO § 102. O direito domiciliar do banco, exercido pela presidência, poderia portanto ter sido violado. Ranft poderia ter se posicionado a respeito disso; um relato acrítico que produz o efeito de uma concordância não é suficiente.

Quanto à suspeita ou aos suspeitos de terem praticado o delito ou de terem participado dele, "junto aos quais" a busca é admissível sob os pressupostos do STPO $\S 102$, Ranft exige, com vistas ao alcance da intervenção no direito fundamental, com boas razões que eles já devem ter o status de acusados. Deve-se concordar com isso. Concretamente esse parece ter sido o caso da funcionária afetada. Ela é chamada várias vezes de "acusada" pela Corte Constitucional Federal na sua sentença de 23.3.1994 ${ }^{51}$. Mas como pode então ser correto que a busca não tenha sido efetuada "junto a" essa acusada, i. é, no seu domicílio e em outras dependências de sua posse, mas sem restrições nas dependências comerciais do banco, onde ela era, conforme o seu cargo na hierarquia, apenas detentora em nome ou cumprimento de ordens ou instruções de outrem [Besitzdienerin]?

Ocorre que Ranft ressalta, no caso das "medidas processuais penais contra" o banco afetado, que a Corte Constitucional Fe-

\footnotetext{
48. wistra 1994, 221 (222) = StV 1994, 353 (354), respecticamente na parte inferior da coluna direita.
}

49. Contra uma tal "suspeita contra a empresa" e em favor da necessidade da imputabilidade individual pronunciam-se também Papier/Dengler, BB 1996, 2593 (2600).

50. wistra 1994, 221 (222) = StV 1994, 353 (354), respectivamente no centro da coluna direita.

51. wistra 1994, 221.

Revista da Faculdade de Direito da UFRGS, v. 16, 1999 deral teria "registrado com muita precisão" a existência dos fundamentos da intervenção [scil. no direito fundamental. $\bigcirc$ tradutor]. A título de fundamentos da intervenção ele reproduz as declarações de um funcionário do banco em uma ação cível concluída e a alegação da funcionária acusada, independente da referida ação. Não fica claro o que Ranft quer dizer com o termo "fundamentos da intervenção". Caso ele se refira aqui às "circunstâncias unívocas do delito" ${ }^{2}$ por ele mencionadas, incorre em erro, pois não se pode extrair nada das duas decisões da Corte Constitucional Federal de 23.3.1994 e 13.12.1994 ${ }^{53}$ que pudesse explicar a sua tese. $\mathrm{Na}$ decisão de 23.3.1994 ${ }^{54}$ a corte afirma tão-somente que a funcionária afetada "declarou que o rascunho lhe serviria como recurso mnemotécnico, pois ela seria freqüentemente perguntada, quando os clientes tivessem esquecido o número da sua conta bancária". Isso torna improcedente a constatação de Ranft de que existiria "uma alegação suficientemente informativa [aussagekräftig] de uma funcionária acusada que teria mantido um 'rascunho'". Tudo indica que a funcionária organizou o rascunho motu proprio, utilizando-o com exclusividade, de modo que o referido documento não foi nenhum documento do próprio banco.

Além disso o banco alegou, conforme a decisão da Corte Constitucional Federal de 23.3.1994, "que seria um caminho

absolutamente usual efetuar pagamentos a partir de uma conta bancária de dinheiro não-declarado [Schwarzgeld] no Luxemburgo, mediante cheques ao portador". Tal afirmação da corte não contém nenhuma "declaração de um funcionário do banco". Muito pelo contrário, a explana ção reproduzida provém de uma ação cível tendo sido completamente separada do seu contexto pela Corte Constitucional Federal. Mas Ranft não pôde reconhecer essa faceta dos fatos. Deve-se negar univocamente a pergunta se é legalmente defensável o procedimento jurídico de com binar em uma suspeita inicial uma ação individual de cumplicidade e uma explanação de tempos passados, inteiramente irrelevante para as sindicâncias tributáriopenais, para depois investigar um banco com os métodos da busca sistemática. Isso é documentado mais especificamente pela decisão da Corte Constitucional Federal de 13.12.1994 ${ }^{55}$. Aqui a corte só pôde contestar a explicação do banco de que as de. clarações do funcionário na ação cível teriam sido compreendidas de forma equivocada e afirmariam tão-somente que a forma da transferência de dinheiro do Luxemburgo para a Alemanha por meio de cheques ao portador seria um procedimento usual de pagamento, afirmando que tal interpretação não seria cogente e por isso não se prestaria a impedir o efeito reforçador da suspeita, causado pela declaração.

52. WiB 1996, 49 (51) (Seçăo III, ño 3 a).

53. wistra 1994, 221 = StV 1994, 353, bem como wistra 1995, 139

54. wistra 1994, $221=$ STV 1994, 353

55. wistra 1995,139 (140), no centro da coluna direita.

* Segundo informação fornecida pelo autor, o equivalente inglês de conto pro diverse é account to whom and to what it may concern. [N. do T.] 


\section{Suspeita de cumplicidade na} sonegação de impostos

Para a realização de buscas no banco o tribunal de primeira instância de Düsseldorf fundamentou a suspeita de cumplicidade na sonegação de impostos no fato de que "em infração consciente das normas do Código Tributário Nacional (AO § 154) as movimentações financeiras eram efetuadas através de contas do banco, a saber através de contas de caixa e contas do tipo conto pro diverse a, ao in vés de através de contas de clientes", e isso "de modo acobertador" ${ }^{56}$. A decisão ex tremamente sucinta do recurso, proferida pelo tribunal regional de Düsseldorf, que já declarara anteriormente ilícito o processamento de negócios de titulares conhecidos de contas por meio de contas do tipo conto pro diverse ${ }^{57}$, endossou essa opinião: "Esse modus operandi usual, freqüentemente aplicado, [...] infringe $\mathrm{AO}$ $\S 154$." O que foi novo na decisão sobre o recurso foi a menção de que a transferên cia de dinheiro tinha sido efetuada "em contas numeradas [...] no Luxemburgo" 58 $\mathrm{Na}$ sua decisão de 23.3.1994 ${ }^{59}$ a Corte Constitucional Federal explica que "dinheiro de clientes" teria passado "por con tas do tipo conto pro diverse", "mediante infração da prescrição de AO § 154". Nes sa base também Ranft reconhece uma in -

fração inequívoca "do sentido e do teor literal de $\mathrm{AO} \S 154$, que conduz forçosa mente à suspeita de cumplicidade na sonegação de impostos".

Os tribunais envolvidos e Ranft não puderam esclarecer a contento os fatos e acolheram constatações supostamente pertinentes sem efetuar um exame próprio suficientemente crítico ${ }^{60}$. Hamacher ${ }^{6}$ mostrou com muitos detalhes e grande conhecimento de causa que não foram utilizadas nem as contas internas do banco nem as contas do tipo conto pro diverse localiza das entre as contas puramente internas do banco e as contas referidas ao cliente, mas uma conta da sociedade luxemburguesa afiliada junto à matriz alemã, conseqüentemente, uma conta bancária típica para operações de correspondência entre bancos nacionais e estrageiros. Contrariamente à decisão sobre o recurso, tomada pelo tribunal regional de Düsseldorf e também nesse sentido citada positivamente por Ranft, essa conta não é nenhuma conta numerada que, como se sabe, seria inadmissível na Alemanha, justamente com base em $\mathrm{AO} \S 154$ II, mas também no Luxemburgo, com base na prescrição pre cedente de RAO $\$ 163$, ainda vigente nes se país ${ }^{62}$. Mas também não existe nenhuma infração de $\mathrm{AO}$ § 14 I e III, pois de acordo com o teor literal e a jurisprudência perma- nente da Corte Constitucional Federal ${ }^{63}$ se trata aqui apenas das relações entre o titular da conta (sociedade luxemburguesa afiliada) e o banco alemão (sociedade matriz alemã), ao passo que as pessoas dos depositantes ou dos destinatários dos pagamentos somente entraram "no campo visual do interesse do legislador" com o $§ 2$ da Lei sobre a Lavagem de Dinheiro ${ }^{64}$.

Ranft duvidou, ao que tudo indica, se a alegada infração de $\mathrm{AO} \S 154$ possa ser sustentada. De qualquer modo, ele recorre imediatamente após a sua afirmação de uma infração inequívoca do teor literal e do sentido de $\mathrm{AO} \S 154$, que conduziria forçosamente à suspeita de cumplicidade na sonegação de impostos - a uma fundamentação auxiliar: "Abstraindo disso, a infração de $\mathrm{AO} \S 154$ não constitui uma ação de cumplicidade de um funcionário do banco". $\mathrm{O}$ que ele cita depois como outro tipo de ação de cumplicidade, o "apoio psíquico" ou a "formulação de um conselho", não tem maior força. Desprovida de objeto é a acusação de conivência baseada em anotações não-oficiais "sobre a correlação entre contas numeradas e os seus titulares"; pois não havia aqui contas numeradas, conforme foi exposto. Contas com proteção do nome são, no entanto, legalmente admissíveis.

63. WM 1994, $2270=$ DB 1995, 423.

64. Hamacher, DB 1995, 2286

65. wistra 1995, 139 (140).

66. Carl/Klos, wistra 1994, 211 (213)

*****A expressão 'vorauseilender Gehorsam', literalmente 'obediência por antecipação', tem sido utilizada nas últimas décadas por sociólogos, cientistas políticos e jornalistas para descrever um padrão comportamental tradicionalmente difundido na sociedade

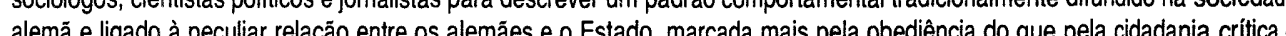
participativa Podecu a norma legal (lei, decreto, portaria administrativa), antes dela ter sido proposta discutida ou promulgada. [N. do T.]

62. Hamacher, DB 1995,2285 
sim." Tal imperativo legal inexiste no caso em pauta. AO § 154 não vale para operações de depósitos bem como de pagamentos em espécie e o $\$ 2$ da Lei sobre a Lavagem de Dinheiro somente abrange parcialmente tais operações ${ }^{67}$. Nesse sentido a instituição bancária pode defender-se: 0 banco e os seus funcionários não disponibilizaram um serviço bancário usual que infringisse as leis, por ocasião da organização dos pagamentos entre o Luxemburgo e a Alemanha. A interposição de uma conta de correspondência é absolutamente necessária por razões contábeis pois a técnica bancária não permitiria efetuar pagamentos transfronteiriços sem contas dessa natureza. Na organização e no processamento de movimentações de dinheiro e eventuais movimentações patrimoniais de outra natureza entre a sociedade matriz alemã e a sociedade afiliada no Luxemburgo questões tributárias ou de direito penal tributário não foram consideradas. O "ocultamento" da identidade de clientes individuais dos bancos não foi o objetivo da organização dos pagamentos. Muito pelo contrário, essa organização orientou-se segundo critérios de otimização gerencial e correspondeu a todas as regulamentaçóes do direito econômico internacional, da legislação regulamentadora da instituições bancárias, da legislação sobre a lavagem de dinheiro e do Código Tributário Nacional. À medida que a identidade

do cliente individual do banco não pode ser constatada a partir de lançamentos individuais, o cliente faz uso da liberdade constitucionalmente assegurada do direito à autodeterminação informacional ${ }^{68}$; sem fundamento legal, o banco e seus funcionários não estão autorizados nem obrigados a restringir ad libitum ou para satisfazer os órgãos tributários o desejável anonimato do cliente.

As explanações de Hamacher sobre o "sistema de dissimulação" teriam merecido uma consideração crítica por parte de Ranft. Nesse caso ele teria se ocupado mais circunstanciadamente com as idéias desenvolvidas com relação ao direito penal material acerca do que é profissionalmente típico, i. é, social ou profissionalmente adequado e nesse sentido não passível de punição na atividade de um funcionário de banco ${ }^{69}$.

Embora Ranft se mostre tão convicto na suspeita da cumplicidade na sonegação de impostos, ele ainda reflete sobre a "materialização [Verdichtung] de uma suspeita concreta de prática de delito que fundamenta um mandado de busca", reportando-se ao comportamento publicitário "dos bancos". Com isso ele retoma uma idéia de Streck ${ }^{70}$. Mesmo se considerarmos que a publicidade freqüentemente exagera, parece ser possível afirmar que a publicidade de uma empresa se presta a dar certos

67. Hamacher, DB 1995, 2286; nesse sentido também Otto, StV 1994, 409 (410 no 4 a).

68. Papier/Dengler, BB 1996, 2541 (2545).

69. Cf. as notas de rodapé 4 a 7, supra; Ranft cita apenas a observação à sentença, feita pelo seu colega bávaro Otto, StV 1994, 409, que reproduz no $n^{0} 2$ a bibliografia especializada publicada até esse momento.

70. DStR 1993, 342 (346); cf. nota de rodapé 12, supra.

O equivalente inglês desse termo é, segundo informaçăo do autor, withholding tax on interest. [N.d.T.] esclarecimentos acerca dos seus atos empresariais efetivos e dos seus objetivos. Mas tal inferência se torna problemática se o com portamento publicitário de todo um ramo da economia, e.g. "dos bancos", deve materiali zar a suspeita de prática de delito contra um membro desse ramo ou contra os seus funcionários. Assim procede quem cita concretamente a publicidade (escandalosa) de um determinado banco e se satisfaz com relação à outras instituições creditícias com uma menção genérica de que elas se teriam exposto, apesar da publicidade discreta, à suspeita de "dificultar a implementação dos direitos de tributação" com ajuda de "vias não usuais de remessa e pagamentos".

Não importa como a natureza e as modalidades da publicidade diante dos cli entes possam ter motivado reações de des vio, a Deutsche Bundesbank se preocupa com os maciços fluxos de recursos financeiros para o exterior, aos quais corresponde o decepcionante volume bruto do steuerlicher Zinsabschlag ${ }^{b}{ }^{71}$. Por razões relacionadas à política do mercado de capitais, a Deutsche Bundesbank pleiteou expressamente que o pagamento de juros e o resgate de títulos ao portador no exterior por ocasião de pres tações financeiras de devedores ou emiten tes alemães fossem eximidos do imposto sobre o Zinsabschlag ${ }^{72}$. Muitos argumentos favorecem a tese de que os custos de refinanciamento da federação através das obrigações federais teriam aumentado com uma tributação na fonte. Mas o steuerlicher Zinsabschlag produz custos de refinanciamento contabilmente menores, se o Estado enquanto tomador de crédito ou emitente de obrigações avalia, em seu benefício na estimativa do seu montante de financiamento, que credores de juros se apropriariam dos rendimentos à margem da tributação, não querendo assim compensar o ônus fiscal com a definição do índice de juros. Essa especulação intencional do Estado tomador de créditos contradiz a tentativa do Estado enquanto credor de tributos de forçar o Zinsabschlag por meio de medidas de repressão a fraudes fiscais, pois conforme a Corte Constitucional $\mathrm{Fe}$ deral ${ }^{73}$ a igualdade de tributação deveria ser assegurada também na implementação da cobrança dos impostos.

\section{Identificação de clientes bancários como possíveis autores principais do delito}

Ranft reconhece corretamente como um "problema adicional da busca em bancos" que por um lado os supostos cúmplices podem ser mais ou menos identificados nas pessoas dos funcionários dos bancos,

71. Deutsche Bundesbank, Relatório Mensal de janeiro de 1994, p. 45 (49).

72. V. BT-Dr 12/2736, manifestação do representante da Deutsche Bundesbank em 6.5.1992, reproduzido na p. 33 em cima, à direita, $10 c$ c. cit:. "[...] Ela [scil. a introdução de um procedimento de informação referente a rendimentos de capitais em benefício da administração fazendária] poderia provocar uma pronunciada fuga de capitais que conduziria a uma nítida elevação do índice de juros, resultando em onnus adicionais para o setor publico e o setor privado bem como para a economia em geral. Tal medida poderia dificultar o financiamento dos custos da uniticação alemă. Em concordância com o pronunciamento do representante da Deutsche Bundesbank na audiência realizada em 6.5.1992 as bancadas da coalizão governamental advertem contra o perigo de testar a tese de que capitais emigrados para o exterior estariam em última instância disponíveis para o mercado interno de capitais pela via do refinanciamento.As bancadas são de opinião de que um procedimento de informação para fins de controle baseado no perigo da saída de capitais, apontado pela Deutsche Bundesbank, envolveria um elevado risco financeiro."

73. BVerfGE 84,239 
mas que, por outro lado, os clientes enquan to "autores principais do delito via de regra somente podem ser identificados com base na realização de buscas".

Se, portanto, as sindicâncias se dirigem apenas aparentemente contra o banco, "procurando-se em verdade os indícios que podem fundamentar a suspeita da prá tica de delito contra clientes ainda não identificados do banco", tal busca é inadmissível também na opinião de Ranft, pois ela so mente poderia ser fundamentada em StPO $\S 103$ e, sobretudo, por faltar a suspeita inicial necessária para uma tal "busca sistemática". Mas é precisamente essa a situação do caso em pauta; não se pode imaginar um caso claro de sindicância ${ }^{74}$.

Ranft, no entanto, não quer aplicar os princípios por ele mesmo estabelecido nos casos "nos quais se deve partir da suposição de uma cumplicidade sistemática, or ganizada na sonegação de impostos". Segundo Ranft, essa suspeita parece ter sido pertinente no caso inicial [Ausgangsfall], pois ele concorda com a decisão da Corte Constitucional Federal de 13.12.1994, ain da que somente "quanto ao resultado".

As explanações de Ranft sobre a pro porcionalidade estão dimensionadas segun do o mesmo padrão. A proporcionalidade deveria ser observada "sob muitos aspec tos", justamente no direito regulamentado de buscas e apreensões; a intervenção em direito fundamental não deveria ser efetu ada se a suspeita de delito se fundamentas se em indícios de menor força de convicção.

Por outro lado, "a ajuda sistemática na sonegação de impostos, se ela com efeito existe como a Corte Constitucional Federal a considera possível segundo os indícios existentes [...]" teria "traços claros de criminalidade organizada, que no caso do comportamento de igual direcionamento de vários grandes bancos" poderia resultar em danos no valor de dezenas de bilhões de marcos; esse argumento deveria desempenhar na ponderação dos prós e dos contras um papel [e Ranft provavelmente quer dizer aqui: o papel decisivo]

Ranft se refere também ao que "também a Corte Constitucional Federal" considera possível. Mas ele ultrapassa posterriormente a reserva que a prudência recomenda nesse caso, ao conferir a etiqueta "traços claros de criminalidade organizada" aos fatos em pauta. Com isso ele ataca injustificadamente os bancos afetados. Um traço distintivo da criminalidade organizada é o seu modus operandi transfronteiriço (transnational crime), o fato dela atuar, similarmente às organizações terroristas, na forma de sociedades criminosas, colocando em risco a segurança do Estado bem como minando, em última instância, a estrutura de nações inteiras. Exemplos disso são o tráfico de armamento bélico (inclusive de matérias físseis), o tráfico de drogas, a lavagem de dinheiro, o tráfico de pessoas, a prostituição e a cobrança chantagista de 'contribuições de proteção' 75 .

$\mathrm{Na}$ seqüência de um tal ataque não deixa de causar estranheza se Ranft afirma,

74. Cf. a argumentação pormenorizada de Leisner, BB 1994, 1941 (1944, 1945 s.), bem como BB 1995, 525 (527 s.). 75. Natorp, no diário Frankfurter Allgemeine Zeitung de 4.12.1996, p. 16. na discussão subseqüente de uma concordância com o exame dos registros bancários, obtida sem pressão, que a motivação, de evitar danos maiores, e.g. tocantes à "boa reputação", ainda não indicia nenhuma situação de pressão.

Depois de formular a acusação da criminalidade organizada, Ranft passa a de dicar a sua atenção aos detalhes da busca e apreensão ${ }^{76}$, que praticamente não têm mais nenhuma relação com o caso inicial e não podem mais ser comentadas extensamente por já terem sido usadas nas explanações supra.

\section{Resumo}

Ex positis deve-se registrar o que segue:

1. Na sociedade contemporânea os bancos não' são mais instituições intocáveis especialmente em conexão com a acusação da sonegação de impostos pelos seus clientes, eles não gozam mais, junto aos órgãos encarregados da persecução penal, junto aos tribunais e também na bibliografia especializada juspenalista bem como processualpenalista, de nenhum crédito que ultrapasse o que está assegurado a qualquer outra pes soa ou instituição.

2. Em última instância, artigos especializados em Direito Processual Pena como o de Ranft não tocam o cerne do problema, pois na busca e apreensão efetuados em dependências de bancos as medidas persecutórias penais contra indivíduos só interessam do ponto de vista formal, con

76. WiB 1996, 49 (52-58) (Seçōes IV-XI)

77. Ct. Papier/Dengler, BB 1996, 2593 (2596) sistindo seu objetivo verdadeiro no impedimento de pagamentos anônimos transfronteiriços e na conseqüente redução dos patentes déficits operacionais da tributação vigente dos juros ${ }^{77}$. Sempre que se fala do abuso das organizações bancárias para fins de sonegação de impostos, devese contrapor a esse argumento o abuso do instrumento juspenalista para fins de política financeira.

3. Tocante a detalhes, a argumentação de Ranft se mantém, conforme se deve reconhecer, nos limites do Estado de Direito. Isso vale para o seu posicionamento contra a assim chamada busca sistemática [Rasterfahndung] ou para o seu postulado de que o suspeito, junto ao qual se deve efetuar a busca, já

deve ter status legal de acusado. Mas essa virtude deixa de funcionar em nível elementar quando a proteção coerente dos bancos pelo Art. 13을 da Lei Fundamental está em pauta. Embora somente uma funcionária de grau hierárquico muito inferior seja conhecida como acusada, Ranft confere o status de acusado ao próprio banco, culminando na acusação da criminalidade organizada.

4. Procedendo assim, ele aceita com excessiva rapidez fatos imprecisamente le. vantados e erroneamente compreendidos - assim como os tribunais especializados aceitam fatos imprecisamente levantados e erroneamente compreendidos da promotoria pública e como a Corte Constitucional Federal aceita fatos imprecisamente levantados e erroneamente compreendidos 
dos tribunais especializados. Ranft teria melhor compreendido a sua tarefa, tivesse ele refletido sobre como se pode restituir à reserva do juiz a função de uma proteção jurídica preventiva, diante de uma práxis deteriorada nas operações de busca e apreensão ${ }^{78}$.
5. Somente com essa reflexão seria possível garantir uma das áreas mais sensíveis dos direitos fundamentais da pessoa, a saber a liberdade de buscas injustificadas, e impedir a transgressão da fronteira entre o Estado de Direito e o estado policial ${ }^{79}$

\section{Integração Jurídica na Europa}

\section{Haxniet Christiane Litschex}

Professora Visitante DAAD/CAPES na Faculdade de Direito da Universidade Federal do Rio Grande do Sul; Doutora em Direito pela Universidade de Hamburgo, Alemanha.

Agradeço a minha cara colega Professora Doutora Clándia Lima Marques que sugeriu e facilitou a produçāo e publicação deste artigo (que apresentei - de forma muito abreviada - como palestra durante o "VI Encuentro de Especialistas en el Mercosur", Rosário, Argentina, 27 e 28 de agosto de 1998) e providenciou material valioso durante viagem ao exterior, ao meu colega, Professor Doutor Luís Afonso Heck, por uma discussão estimulante, ao assistente universitario Cristian Schindler, Heidelberg; que forneceu fontes aqui dificilmente acessíveis e ao bolsista Anderson de Lima Kovalsky, sern cuja ajuda, tanto no âmbito técnico como no âmbito lingüístico, este artigo nunca teria sido escrito. Partes deste trabalho já foram publicadas sob o titulo "Probleme eines Wandels des innerstaatlichen Rechts zu einem europäischen Rechtssystem nach der Rechtsprechung des Europäischen Gerichtshofs" in: RabelsZ 60 (1996) pp. $648-660$ pela própria autora.

\begin{tabular}{|l|l|}
\hline \multicolumn{2}{|c|}{ SUMÁRIO } \\
I. Introdução. & III. A Diretiva como Instrumento Especial da \\
II. Aspectos gerais. & Integração Jurídica. \\
1. O Tribunal das Comunidades Européias na & 1. Nota Preliminar. \\
Estrutura da Comunidade Européia. & 2. Aplicação da Diretiva Não-transformada \\
a. No texto do Tratado da Comunidade & como Sanção. \\
Européia. & a. Necessidade de uma sanção. \\
b. Na realidade. & b. Sanção do efeito direto. \\
c. Osmétodos interpretativos do Tribunal CE. & c. Quiebra da idéia da sanção-Art. 5 Tra- \\
2. Direito Europeu como Sistema Jurídico e & tado CE. \\
as suas Fontes Principais. & 3. Indenização por Falta de Transformação. \\
a. Particularidades do Direito Europeut. & 4. Diretiva e Interpretação. \\
b. Fontes principais de Direito Europeu. & a. Nota preliminar. \\
c. A diretiva: uma norma com caráter es- & b. Interpretação e aplicação. \\
pecifico. & c. Interpretação e solução de conflito de \\
3. Direito Europeu e Direito Nacional. & normas. \\
a. Princípio da subsidiaridade. & d. Abalo de direito interno. \\
b. Primazia. & e. O problema dos métodos. \\
c. Vigência e aplicação. & IV. Conclusões e uma Sugestão. \\
\hline
\end{tabular}

Revista da Faculdade de Direito da UFRGS, v. 16, 1999
78. Cf. para tal também Papier/Dengler, BB 1996, 2541 (2548)

Revista da Faculdade de Direito da UFRGS, v. 16, 1999 